brain must concoct a hallucinated subjective experience of movement which corresponds with the activation of the motor system. This argument harks back to the James-Lange theory of emotion: we are fearful because we tremble rather than we tremble because we are fearful.

Nevertheless, this is a provocative book which, in the long run, could be important, if only for its heuristic effect. Some 35 years after the discovery of REM sleep, Hobson is forcing us to come to grips with fundamental questions. He writes well and the book is nicely illustrated. To set the stage, he presents an interesting history of the parallel developments during the past century in the neurosciences, dream research and psychoanalysis. For these reasons, most of the ideas are readily accessible to the layman, but the specialist will also find much here that is new or interesting. This book will have served its purpose if it stimulates others to consider dreaming from a new psychobiological perspective. One day, perhaps, this will activate others to formulate a new synthesis incorporating both a comprehensive neurobiological and a psychosocial view of dreaming.

J. Christian Gillin is a Professor in the Department of Psychiatry, University of California San Diego, and San Diego Veterans Adminis tration Medical Center, La Jolla, California 92093, USA.

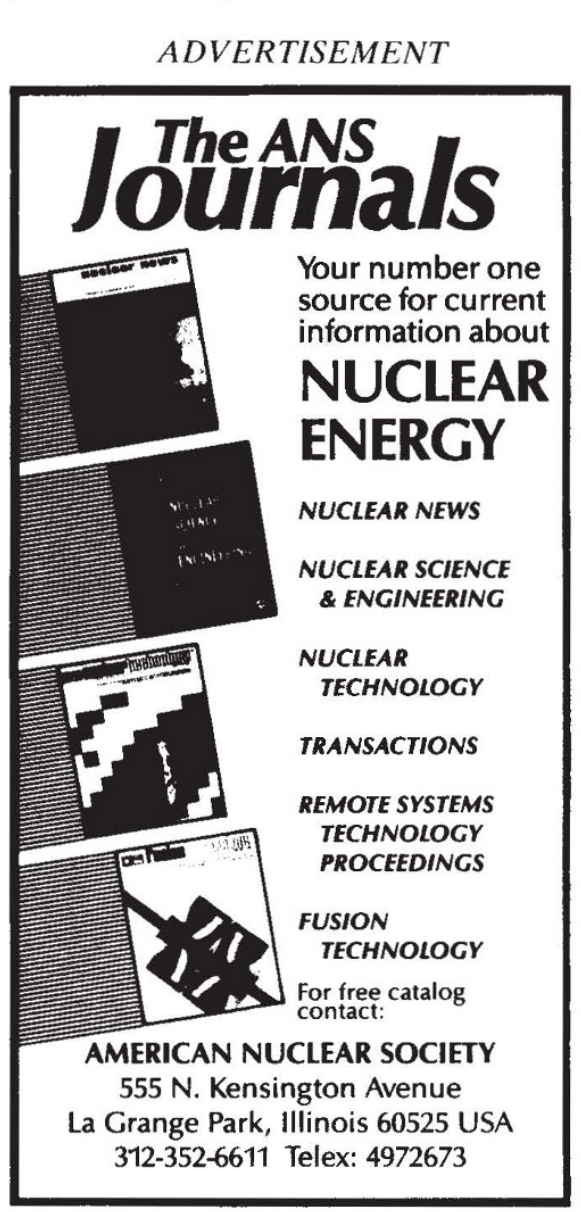

Reader Service No.22

\section{A growing field}

\section{Clive Stace}

Grass Systematics and Evolution. Edited by Thomas R. Soderstrom, Khidir W. Hilu, Christopher S. Campbell and Mary E. Barkworth. Smithsonian Institution Press:1988. Pp.474. \$45, £35.

THE appearance of another sizeable book on grasses should come as no surprise, for the Poaceae, with about 10,000 species, are not only one of the biggest families of plants but by far the most important in terms of human welfare. Our civilizations built up around their cultivation, and our continuing success depends upon them no less today. In recent years several other large families have been the subject of symposia resulting in volumes that have immediately become standard texts. Those on the Apiaceae, Solanaceae, Fabaceae and Asteraceae are excellent examples. That we have had to wait so long for the present volume is a measure of the overwhelming significance of grasses and the vast number of publications that relate to them. On this basis, we should not have to wait too long for a sequel, as there are inevitably many gaps and biases in the book under review.

Until well into the twentieth century grass classification was patently artificial, being little but elementary pigeon-holing of taxa. This was due to the extreme reduction of floral parts and the stereotyping of an immensely successful vegetative structure, and it led to the deliberate search for cryptic micro-characters that might provide the basis for more natural classifications. That such characters were found in abundance, initially by Avdulov (cytology) and Prat (leaf epidermis) in the 1930 s, is part of a success story which has resulted in the Poaceae having a more natural and hence valuable classification than virtually any of the other large families. Hence there are hardly any taxonomic novelties in the present work.

Grass Systematics and Evolution consists of 33 chapters based on papers presented at a symposium held at the Smithsonian Institution in July 1986. It covers topics as wide-ranging as structural diversity (from gametophytes to leaf epidermis), biochemical diversity (from chloroplastDNA to isozymes and flavonoids), reproductive biology, and systematics of the principal groups (the five widely recognized subfamilies each have at least one chapter), including discussion of both phenetic and cladistic methods. As indicated in its title, topics such as plant breeding, ecology and relationships with man and other animals are omitted or scarcely covered. Some subjects that, based upon chapter titles, appear to be treated are found to receive only cursory attention.
For example, "Man and the Grasses: a History" (R. W. Pohl) consists of little over three pages of general chatter, and "Hybridization and Polyploidy in the Poaceae" (J. M. J. de Wet) can do scant justice to the subject in under six pages. Indeed, the vast body of data that has been accumulated under the general headings of cytogenetics and biosystematics is greatly under-represented. It is a lacuna that should be filled in a future volume, along with related topics such as plant breeding, including (as mentioned by Melvin Calvin in the foreword) genetic engineering.

Nevertheless, most of the chapters are written authoritatively, often in a review style, and provide not only an up-to-date picture of many aspects of agrostological research but a source for the basic literature (there is a general bibliography of 71 pages and in all over 2,300 references are included). Readers will frequently have to go to other publications for more details, but this is a book that must be considered the most valuable single work on the family.

Clive Stace is a Professor in the Department of Botany, University of Leicester, Leicester LEl 7RH, UK.

\section{Uniting nations}

\section{R.V. Short}

World Population and the United Nations: Challenge and Response. By Stanley P. Johnson. Cambridge University Press: 1988. Pp.357. Hbk £37.50, \$59.50; pbk $£ 12.95, \$ 22.95$.

This is a Tio Pepe of a book, too dry for the palates of all but the most dedicated aficionados of the subject. The central theme is a retrospective analysis of the activities of the United Nations Fund for Population Activities (UNFPA), created by the United Nations in 1969 and directed until 1987 by that inspired internationalist, Rafael Salas. UNFPA has been responsible for raising large sums of money for population projects, but has tended to use other UN organizations such as UNESCO, ILO, FAO, UNDP, UNICEF and WHO as well as NGOs as its executing agencies. If you are already confused, then take heart the book begins with a glossary of acronyms.

The text is replete with lengthy quotations from UN documents, speeches and minutes of meetings, backed up with extensive tabulations of data, and four graphs and a pie chart by way of light relief. The author is a professional administrator and sometime European parliamentarian with several books of fact and fiction to his credit. But although he 